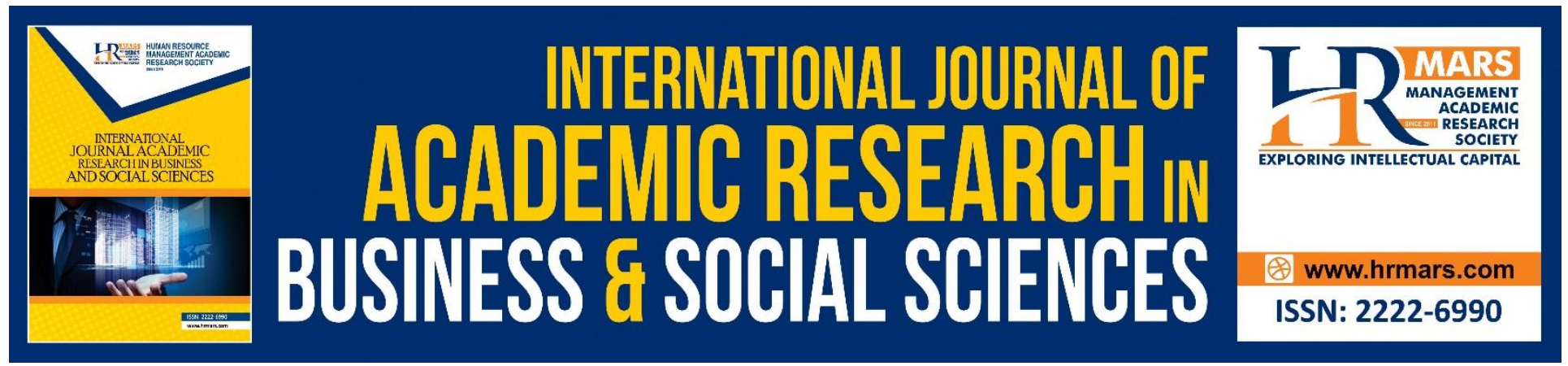

\title{
The Effectiveness of Reality Group Counseling Therapy in Enhancing Multiple Intelligence among Malaysian Students with the Tendency of Problematic Internet Use (PIU)
}

Amin Al Haadi Bin Shafie, Nur Faizah Binti Abdul Kahar, Mohd Khairul Anuar Bin Rahimi, Roslee Bin Ahmad

To Link this Article: http://dx.doi.org/10.6007/IJARBSS/v9-i6/5944

DOI: $10.6007 /$ IJARBSS/v9-i6/5944

Received: 10 April 2019, Revised: 18 May 2019, Accepted: 02 June 2019

Published Online: 24 June 2019

In-Text Citation: (Shafie, Kahar, Rahimi, \& Ahmad, 2019)

To Cite this Article: Shafie, A. A. H. Bin, Kahar, N. F. B. A., Rahimi, M. K. A. Bin, \& Ahmad, R. Bin. (2019). The Effectiveness of Reality Group Counseling Therapy in Enhancing Multiple Intelligence among Malaysian Students with the Tendency of Problematic Internet Use (PIU). International Journal of Academic Research in Business and Social Sciences, 9(6), 247-258.

Copyright: (c) 2019 The Author(s)

Published by Human Resource Management Academic Research Society (www.hrmars.com)

This article is published under the Creative Commons Attribution (CC BY 4.0) license. Anyone may reproduce, distribute, translate and create derivative works of this article (for both commercial and non-commercial purposes), subject to full attribution to the original publication and authors. The full terms of this license may be seen at: http://creativecommons.org/licences/by/4.0/legalcode

Vol. 9, No. 6, 2019, Pg. 247 - 258

Full Terms \& Conditions of access and use can be found at http://hrmars.com/index.php/pages/detail/publication-ethics 


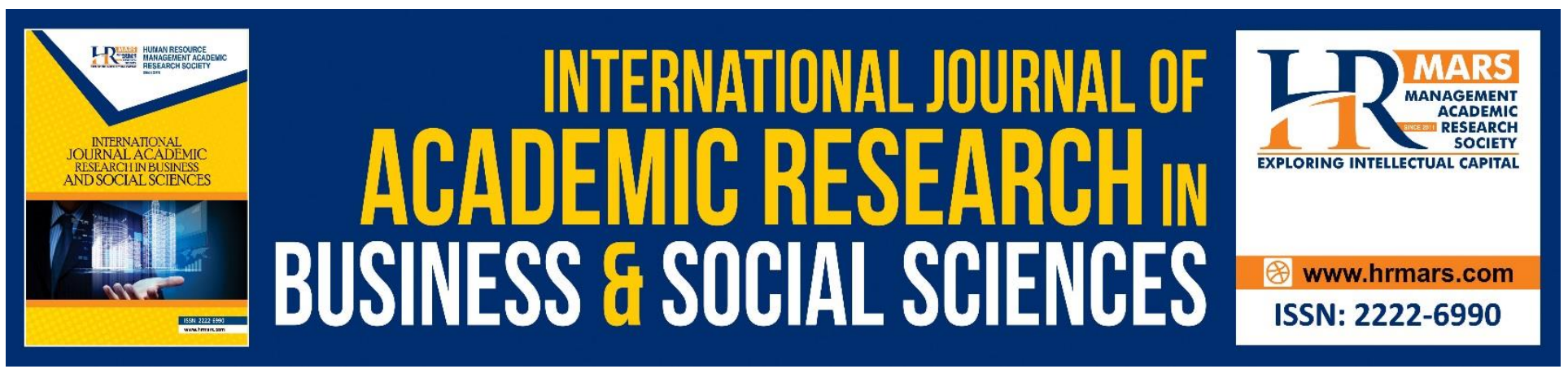

\title{
The Effectiveness of Reality Group Counseling Therapy in Enhancing Multiple Intelligence among Malaysian Students with the Tendency of Problematic Internet Use (PIU)
}

\author{
Amin Al Haadi Bin Shafie, Nur Faizah Binti Abdul Kahar \\ Asian Centre of Research on Drug Abuse (ACREDA), Universiti Sains Islam Malaysia, Bandar Baru \\ Nilai, 71800, Nilai Negeri Sembilan, Malaysia. \\ Email: amin@usim.edu.my
}

\author{
Mohd Khairul Anuar Bin Rahimi, Roslee Bin Ahmad \\ Faculty of Leadership \& Management, \\ Universiti Sains Islam Malaysia, \\ Bandar Baru Nilai, 71800, Nilai Negeri Sembilan, Malaysia
}

\begin{abstract}
This study was aimed to explore the effectiveness of group reality therapy in increasing students' multiple intelligence, focusing on interpersonal skills. We employed quasi-experimental and pretest - posttest design with control group. The statistical population comprised primary and secondary school students in Malaysia, in which out of 24 students were from primary school and 22 students were from secondary school. Participants were selected purposely by school counselors based on students' vulnerability of having problematic internet use (PIU). Participants then were randomly assigned to the experimental and control groups. The experimental group has undergone counseling session of group reality therapy, while the control group did not receive any intervention. The research tools included Generalized Problematic Internet Use Scale 2 (GPIUS 2) and Interpersonal Competence Questionnaire (ICQ-15). MIX ANOVA was used to analyze the data. The research results revealed that reality therapy in group counseling has increased the students' interpersonal skills $(P<$ 0.05).
\end{abstract}

Keywords: Problematic Internet Use, Multiple Intelligence, Interpersonal Skill, Reality Group Therapy, School Students 


\section{Introduction}

Information and communication technologies have become crucial parts in our lives and do give huge impacts in the lifestyles of today's society. Many people, particularly teenagers, spend much of their time with technological devices for studying, searching for information on the internet, playing games, and communicating. Most of today's activities require the society to use internet. In recent years, as smart phones have become largely available, reaching internet is much easier and number of users is increased (Say \& Batigun, 2016). Internet has become the most import things in today's life and most popular medium utilized by the general population especially among adolescents. Generally, studies of internet use have found several different results regarding the effect of the internet. Some view internet as positive development meanwhile some views it as a negative distractive development.

Internet have allowed people to affordably communicate at long distances as well as performing many tasks, including science, commerce, shopping, paying bills, taking educational classes, working, and keeping in touch with loved ones. Having the world at your fingertips is really helpful nowadays but using it excessively may lead the users to a harmful effects. Some might neglect their important social relationships, their work responsibilities, and even their health because they are too absorbed with their online activities. To some clinicians and researchers, it seemed that online activities could lead to dysfunctional behavior. People might become addicted to internet just as they become addicted to gambling or alcohol. As Internet use exploded in the ensuing decades, concern with what has been called Problematic Internet Use (PIU) or Internet addiction has also grown and suitable intervention must be taken seriously to prevent this issues from becoming worst.

As a result of problematic internet use, several problems are arising. PIU can cause problematic social relationships, lack of motivation, as well as other problems related to psychological health such as social anxiety and fears and affect the development of multiple intelligences and achievement motivation. Students who are likely to experience problematic internet use are reported to not maximize the range of intelligence they possess and may trigger a decrease in motivation of achievement thus affecting their academic performance at school.

To educate students about their responsibilities as students even if they have a problematic internet use, the ideal approach to use is by using a realistic approach. This is based on the basic concepts found in reality counseling on rights, responsibilities and reality. These basic concepts are one of the ways to help students with the tendency of problematic internet use to further develop their intelligence and increase the motivation of learning so that it can improve student academic achievement. Thus, this paper is aimed to identify the effectiveness of counseling therapy used in enhancing multiple intelligent among Malaysian students with the tendency of problematic internet use.

\section{Literature Review}

\section{Problematic Internet Use (PIU)}

The Internet has made life more convenient, saves time and shortens the distance between people. Problematic Internet Use (PIU) is an addictive behavior where are the users have excessively or poorly controlled preoccupations, urges, or behaviors regarding computer use and internet access that lead to impairment or distress (McLean, 2013). According to Breslau, Aharoni, Pedersen, \& Miller (2015), 
PIU it is commonly defined by symptoms associated with addiction, including excessive and compulsive use, tolerance, withdrawal, and impairment. This defination is align with Snyder, Li, O'Brien, \& Howard (2015) which considering PIU as a behavioral addiction with characteristics similar to substance use disorders and young adults have especially high risks of behavioral addictions. They continuing a pattern of excessive use despite adverse consequences which later cause a harmful effects to them. Just like drug addiction, they become tolerance and craving for more internet use as increase in time.

Other researcher describe PIU as use of the Internet that creates psychological, social, school, and work difficulties in a person's life (Beard \& Wolf, 2001). Excessive Internet use in adults has been associated with failed marriages, unemployment, neglected children, and sleep deprivation (Young, 1998). Young's research on problematic internet usage (PIU) has documented associated symptoms and problems, including losing control, craving and withdrawal, social isolation, academic failure, financial problems, job loss, and marital discord. A negative correlation has been reported between time spent playing Internet games and academic performance, and a positive association between violent internet game playing and aggression (Anderson \& Dill, 2000). Not only does excessive Internet use has a negative impact on the mental and physical health of children and adolescents with PIU, it might also increase risk of violence in this age group. Mostly, young people are using the Internet as a form of socialization without realizing the negative impact that may carry. Thus, when Internet use starts to take up a large portion of their time, it does affect their mood, and jeopardize academic and social function and performance, Internet usage may become a problem that may require intervention.

\section{Significance of Study}

This study is important to help students with the tendency of problematic internet use to enhance their multiple intelligence aspects by the intervention of the counseling reality therapy group. Besides that, this study is esteemed to identify the effectiveness counseling therapy used in enhancing multiple intelligent.

\section{Methodology \\ Research design}

This research is an experimental research using quasi experimental design. In the research, participants among those who have a tendency towards Problematic Internet Use (PIU) are selected by the school counselor. Samplings of the study were constituted from primary and secondary school students from selected school in Malaysia. The researcher then administers a pre-test to the experimental group and the control group. Group counseling using reality therapies were applied on the experimental group while there is no counseling intervention in control group. Lastly, a post test was administered to both groups to get the final findings and assess the differences between groups. This study also used repeated measure design where each group member in an experiment is tested for multiple conditions over time or under different conditions. In this case, it is used ordinary repeated measures where the participants are assigned a single treatment, and the results are measured over time. 
INTERNATIONAL JOURNAL OF ACADEMIC RESEARCH IN BUSINESS AND SOCIAL SCIENCES

Vol. 9, No. 6, June, 2019, E-ISSN: 2222-6990 @ 2019 HRMARS

\section{Population and Sampling}

This study was conducted among primary and secondary school students in Malaysia. Total of 46 students were selected as a participants which are 24 of the students from primary school while another 22 students are from secondary school. Sampling procedures in this study was nonprobability sampling which used purposive sampling techniques. A purposive sampling technique is a technique where are the participants are choose purposely based on their tendency of having problematic internet use (Cresswell, 2015).

\section{Instrumentation}

Problematic internet use (PIU)

The PIU variable is measured using the Generalized Problematic Internet Use Scale 2 instrument (GPIUS2) (Caplan, 2010). This instrument consists of 15 item items: Preference for online social interaction (POSI), 3 items (mood-regulation), and 9 items (deficit self-regulation) which consists of 3 items (cognitive preoccupation), 3 item (compulsive internet use), 3 items (negative outcome). This instrument has an alpha Cronbach score of .91.

Interpersonal skill

This variable was measured using the Interpersonal Competence Questionnaire (ICQ-15) instrument developed by Buhrmester, et al (1988). The scores consist of 15 items and a Likert scale with a minimum score of 15 and a maximum of 75 . The score is divided into five categories as follows: very low $(\leq 27)$, low $(\leq 39)$, medium $(\leq 51)$, high $(\leq 63)$ very high $(\leq 75)$. The reliability of the items in this scale after the adjustment process is done by .87 . 


\section{Research Procedures}

1) Instrumentation

- Instruments were distributed to the participants

- Instruments used are:

i. Problematic internet use (PIU)

ii. Interpersonal skill

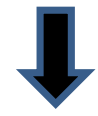

2) Data Collection

- Instruments are then collected for interpretation of the data

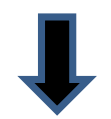

3) Data Analysis

- Sorting the data by using MIX ANOVA analysis design

- compares pre-test and post-test results of control and experiment groups in each treatment while comparing the effectiveness of treatment

4) Findings

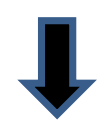

- Interpretation of the results

- Step 1 - 4 are repeated twice for post test 1 and post test 2 findings.

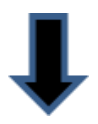

5) Final Findings

- Summarize and synthesising the data

Figure 1: Research Procedures 
INTERNATIONAL JOURNAL OF ACADEMIC RESEARCH IN BUSINESS AND SOCIAL SCIENCES

Vol. 9, No. 6, June, 2019, E-ISSN: 2222-6990 (C) 2019 HRMARS

\section{Data Analysis}

This study uses MIX ANOVA analysis design by anticipating the measurement results will be analyzed from within and between groups. ANOVA test is a rather robust analysis of probability testing (Field, 2013). This study compares pre-test and post-test results of control and experiment groups in each treatment while comparing the effectiveness of treatment for each variable.

\section{Results}

a) Demographic data of PIU among Malaysian students (primary \& secondary school)

Table 1: Demographic Data of PIU Among Primary School Students

\begin{tabular}{cccc}
\hline Level of PIU & No of student(s) & SD & M \\
& & & \\
\hline Severe & 4 & & \\
High & 9 & 13.57 & \\
Moderate & 11 & & 67.92 \\
\hline Total & 24 & 13.57 & \\
\hline
\end{tabular}

The above data shows that the level of problematic internet use (PIU) in which the standard deviation (SD) differs from moderate, high and severe. Primary school students in the moderate category scored highest number or students which are 11 students. Meanwhile, total students that have high category are 9 and 4 students for severe category. Total mean score is 67.92 with a standard deviation score is 13.57 .

Table 2: Demographic Data of PIU Among Secondary School Students

\begin{tabular}{cccc}
\hline Level of PIU & No of student(s) & SD & M \\
& & & \\
\hline Severe & 8 & 62.61 & 12.84 \\
High & 61 & & \\
Moderate & 58 & 62.61 & 12.84 \\
\hline Total & 127 & & \\
\hline
\end{tabular}

The above data shows that the level of problematic internet usage in which the standard deviation (SD) differs from medium, high and very high. High school students in 
medium category are 58 , the high range is 61 students and 8 very high students. Overall has an average score of 62.61 with a standard deviation score of 12.84 .

Thus, it is proven that at every level of education, both primary and secondary schools in Indonesia and Malaysia have students who are experiencing problematic internet usage, so they need to be given further attention in order not to negatively affect the social and academic lives of students.

b) There is a negative impact on the use of Internet Problem (PIU) to students:

1) Decreasing Interpersonal Skills of Primary School Students in Malaysia

Students who have a tendency in the PIU will have a negative impact on interpersonal skills. Demographic data of primary school students who have negative effects as a result of the PIU are as follows:

Table 3: Level Of Interpersonal Skills Among Primary School Students With The Tendency Of PIU

\begin{tabular}{lrrr}
\hline Students $(\mathbf{N}=10)$ & F & Mean & SD \\
\hline Interpersonal Skill & 24 & 60.08 & 5.73 \\
& & & \\
\hline
\end{tabular}

Based on table 3, it can be seen that students with low interpersonal skills are 24 with a mean score of 60.08 and standard deviation of 5.73. This shows that the level of interpersonal skills is in the "Medium" category. Selected students who are chosen as subject of the research were divided into two groups, namely 12 experimental groups and 12 control groups. Experimental group was given reality group counseling to improve interpersonal skills, while control group was not actively treated (placebo). Additionally, after the students were given the reality group counseling, post-test trials were given to determine the level of change.

2) Decreasing Interpersonal Skills of Secondary School Students in Malaysia.

Demographic data of secondary school students who are adversely affected by the PIU are as follows:

Table 4:Level Of Interpersonal Skills Among Secondary School Students With The Tendency Of PIU

\begin{tabular}{llll}
\hline Students $(\mathbf{N}=\mathbf{1 0})$ & F & Mean & SD \\
\hline Interpersonal Skill & 22 & 50.77 & 8.26 \\
\hline
\end{tabular}

Based on table 4, it can be seen that the number of students with low interpersonal skills are 22 with a mean score of 50.77 and standard deviation (SD) of 8.26. This shows that the level of interpersonal skills among secondary students is in the "Medium" category. Students selected as research subjects were divided into two groups, which are 10 of them as experimental group while the other 12 as subjects for control group. The experimental group 
INTERNATIONAL JOURNAL OF ACADEMIC RESEARCH IN BUSINESS AND SOCIAL SCIENCES Vol. 9, No. 6, June, 2019, E-ISSN: 2222-6990 @ 2019 HRMARS

was given the reality group counseling to improve interpersonal skills, while the control group was not given active treatment (placebo). Additionally, after the students were given the reality group counseling, post-test were given twice to students to determine their level of change.

c) Testing on the effectiveness of the reality group counseling in enhancing Interpersonal Skills has been conducted among primary and secondary students in Malaysia.

The statistical analysis results that explain the application of Reality group counseling that influence interpersonal skills development are as follows:

Table 5: The Effectiveness of Reality Group Counseling In Enhancing Interpersonal Skills

\begin{tabular}{lccccc}
\hline Efeects & SS & DF & MS & $F$ & $p$ \\
\hline $\begin{array}{l}\text { Univariate Analysis } \\
\text { (repeaeted measurement) } \\
\text { Measurement *Group }\end{array}$ & 225.75 & 1.75 & 128.99 & $4.20 *$ & .027 \\
$\begin{array}{l}\text { Contrast Analysis } \\
\text { (Uji One Way Anova) }\end{array}$ & & & & & \\
$\quad$ T1-T2 & 360.37 & 1 & 360.37 & $4.58^{*}$ & .044 \\
T2-T3 & 315.37 & 1 & 315.37 & $6.05^{*}$ & .022
\end{tabular}

In Table 5, we can see the correlation between repeat measurements and the level of interpersonal skills students possess. The statistical data between recurring measurements with experimental and control group showed interaction between the two $(F=4.20, p<0.05)$. both of these statistical data are changes in interpersonal skills level from pre-test, post-test, to follow up on each student in two study groups (experiments and controls) have shown a significant difference. In other words, the interventions given to the experimental group and the control group are different.

The difference in results can be seen from the results of contrast analysis between measurement and group (table 5). The relationship between T1 and T2 indicates there is a significance between the two, where there is an increase in yields between the first measurements and the second measurement $(\mathrm{F}=4.58, \mathrm{p}<, 05)$. The same applies to $\mathrm{T} 2$ to $\mathrm{T} 3$, where the analysis results show there is a signification between the second measurement and the third measurement $(F=6.05, p<, 05)$. The results of the findings have shown that intervention (Reality group counseling) is very effective in improving student interpersonal skills significantly and is still sustained without intervention provided to students.

\section{Discussion}

A Reality group counseling approach is chosen to test the extent of its effectiveness in improving interpersonal of participants with the tendency of problematic internet use. Reality therapy bringing 
an approach that state, each individual has control over their own behavior and is responsible for the choice he made (Walter, Lambie, \& Ngazimbi, 2008). William Glasser, the founder and writer of the book Reality Theory (1965) state that group sessions based on reality theory tend to be person centered and focus on the present. During the session, reality theory can helps to enlighten students about the five needs that have to be met daily so that they can control their behavior. Through this group sessions, students have to self evaluate their behaviors and have a clear vision that what they are doing is unwanted.

Data analysis has shown that reality group counseling approach is effective in improving interpersonal skills. It can be seen that interpersonal skills is increasing significantly. From the data of table 5, we can see a significant relationship between the result of T1 (pre-test) and T2 (post-test 1), where is the score is $p=0.044(F=4.58, p<, 05)$. The same applies to T2 (post-test 1 ) to T3 (post-test 2 ), where the analysis results show there is a signification between the second measurement and the third measurement, where is $p=0.022(F=6.05, p<, 05)$. Thus, the results of the findings have shown that the intervention (reality group counseling) is very effective in improving student interpersonal skills significantly and is still sustained without intervention provided to students.

This might be due to the nature of group counseling that encouraging communication among members of the group through discussion on the related issue. The atmosphere will encourage members of the minority groups to explore issues in greater depth and encourage personal development among them. Individuals suffering from PIU will experience some mental health issues such as insomnia, depression, anxiety, emotional disturbances, low resilience and personality disorders (Laconi \& Chabrol, 2017). Farnoodian (2006) reported that reality group therapy is effective on mental health and self-esteem of students. The aim of reality therapy is to help client once again control his life. Glasser' method teaches individuals to choose their own situations by choosing better situation and taught individuals to accept their responsibilities.

Group therapy provides an opportunity for individual to speak out and receiving feedback from other group members. It is a process that continuously enhances the group's dynamic through continuous interactions between groups which can indirectly enhance the interpersonal skills of students. Through participation of individuals in the group session, it helps to strengthen ones social skills and networking with others. Intervention of reality group therapy help people become aware with their personal issues and learn to be more responsible on themselves (Hajhosseini, Lavasani, \& Beheshti, 2017). Furthermore, through the session using reality therapy, it helps them to reconsidering their choices to ensure what is best for their life. Hence, during the reality group counseling process, interpersonal skills are more skillfully hone due to the effects of the built-in interaction which resulting in increasing of the participants' interpersonal skills level.

\section{Conclusion}

Glasser's reality theory is proven can help students work on their problem behaviors. Uses of the right approach can helps to alleviate students' problem behaviors and improve their academic achievement. Through reality theory, it can empower students to become more self-aware of their actions and can help them to understand themselves better. Reality Therapy approach which was founded by William Glasser in 1965 suggests that any kind of issues arise because of individuals' basic needs is not met. Individuals can have control on their own behavior if their all five basic needs are 
successfully met. Glasser believed that an attempt for behavior change will be more successful if it is comes from one's own desire rather than attempt to follow others. This is because an individual knows themselves better.

Glasser saw the human being as motivated by these five needs which are power, love and belonging, freedom, fun and survival. All behavior is aimed at fulfilling all these five psychological needs. This approach promoting the students to deal maximize with their real-self. When students' real-self is well established, it helps them to detect their own strength and weaknesses which results in increase of their self-potential. Effective satisfaction of these needs results in a sense of control on person's self-actualization, self-fulfillment and becoming fully functioning person. As a conclusion, the implementation of reality group counseling as the intervention for students with problematic internet use is proven successful in enhancing their interpersonal skills due to the nature of the approach itself which are based on conscious behavior, wants, needs and perceptions of human being.

\section{Novelty}

Reality group therapy approach enhance Multiple Intelligence Among Malaysian Students with the Tendency of Problematic Internet Use (PIU) due to it nature which are focusing on individual basic psychological needs.

\section{References}

Afaneh, I., \& Khazender, N. (2004). Levels of Multiple Inteligences for Basic Education Students in Gaza and Its Relationship with Achievement in Mathematics and Tendencies Towards It. Journal of Human Studies 12(2), 323-366.

Beard, K. W., \& Wolf, E. M. (2001). Modification in the Proposed Diagnostic Criteria for Internet Addiction. Cyber Psychology \& Behavior, 377 - 383.

Breslau, J., Aharoni, E., Pedersen, E. R., \& Miller, L. L. (2015). A Review of Research on Problematic Internet Use and Well-Being With Recommendations for the U.S. Air Force. Santa Monica, Calif.: RAND Corporation.

Capuzzi, D., \& Stauffer, M. D. (2016). Counseling and Psychotherapy: Theories and Interventions (Sixth Edition). USA: American Counseling Association.

Chang, J. P. C., \& Hung, C. C. (2012). PROBLEMATIC INTERNET USE. Dalam IRey JM (ed), IACAPAP eTextbook of Child and Adolescent. Geneva: International Association for Child and Adolescent Psychiatry and Allied Professions.

Devlin, B. M. (2010). Effects of Students' multiple Intelligences on Participation Rate of Course Components in a Blended Secondary Family and Consumer Sciences Course. Didapatkan dari Graduate Theses and Dissertations, 11286: https://lib.dr.iastate.edu/etd/11286

Farnoodian, P. (2006). The Effectiveness of Group Reality Therapy on Mental Health and Self-Esteem of Students. International Journal of Medical Research \& Health Sciences, 18-24.

Gardner, H. (1993a). Frames of Mind: A Theory of Multiple Intelligences. New York: Basic Books. Gardner, H. (1993b). Multiple Intelligences: The Theory in Practice A Reader. New York: Basic Book. 
INTERNATIONAL JOURNAL OF ACADEMIC RESEARCH IN BUSINESS AND SOCIAL SCIENCES

Vol. 9, No. 6, June, 2019, E-ISSN: 2222-6990 (C) 2019 HRMARS

Hajhosseini, M., Lavasani, M. G., \& Beheshti, M. R. (2017). Effectiveness of Group Counseling based on Reality Therapy on Academic Procrastination and Behavioral Self-Regulation of Students. Int J Behav Sci. (IJBS), 167-172.

Howatt, W. A. (2001). The Evolution of Reality Therapy to Choice Therapy. International Journal of Reality Therapy, 21 (1), 7 - 12.

Lan, C. M., \& Lee, Y. H. (2016). The Guidance Effects of Students with Internet Addiction in Taiwan. The Caspian Sea Journal 10 (1), 91 -95.

Loyd, B. D. (2005). The Effects of Reality Therapy/Choice Theory Principles on High School Students' Perception of Needs Satisfaction and Bahavioral Change. International Journal of Reality Therapy, 25(1), 5 - 9.

McKenzie, M. (2005). Multiple Intelligence and Instructional Technology. Washington, DC: International Society for Technology in Education (ISTE).

McLean, S. (2013). Problematic Internet Use. Didapatkan dari VICTORIA State Government Education

Purwanto, E. (2014). Model Motivasi Trisula: Sintesis Baru Teori Motivasi Berprestasi. Jurnal Psikologi 41(2), 218-228.

Say, G., \& Batigun, A. D. (2016). The Assessment of the Relationship between Problematic Internet Use and Parent-Adolescent Relationship Quality, Loneliness, Anger, and Problem Solving Skills. Dusunen Adam The Journal of Psychiatry and Neurological Sciences, 324 - 334.

Snyder, S. M., Li, W., O'Brien, J. E., \& Howard, M. O. (2015). The Effect of U.S. University Students' Problematic Internet Use on Family Relationships: A Mixed-Methods Investigation. PLOS ONE 10(12): e0144005. doi:10.1371/journal.pone.0144005, 13. 